\title{
Priority Based Uplink Scheduling Scheme for WiMAX Service Classes
}

\author{
Kire Jakimoski \\ FON University, Faculty of Information and Communication Technology, Skopje, Republic of Macedonia \\ E-mail: kire.jakimoski@fon.edu.mk
}

Toni Janevski

Ss. Cyril and Methodius University, Faculty of Electrical Engineering and Information Technologies, Skopje, Republic of Macedonia

E-mail:tonij@feit.ukim.edu.mk

\begin{abstract}
IEEE 802.16 standard supports five different service classes in order to support different needs of the mobile users with different QoS criteria. But, this standard doesn't specify admission control and scheduling mechanisms and so far many solutions are proposed in the science world. In this paper we propose priority based uplink scheduling scheme for IEEE 802.16 standard that improves the QoS performances of the five W iMAX service classes, especially of the ertPS service class. Simulation experiments and analysis are done choosing the most adequate WiMAX simulator and the ns-2 simulation tool. Traffic load of the ertPS connections is changed from low to high in order to perform detailed performance analysis of the results. Results given in average delay, average jitter and average throughput are evaluated and compared with so far known uplink scheduling mechanis $m$. The results show that our proposed uplink scheduling scheme based on the priority of the service classes improves the QoS performances especially in high loaded scenarios.
\end{abstract}

Index Terms - Delay, Jitter, Serv ice Class, Throughput, Uplink Scheduling Scheme, WiMAX

\section{Introduction}

The broadband wireless access (BWA) system designed for wireless metropolitan area networks, WiMAX/802.16 is nowadays already $4 \mathrm{G}$ wireless network technology. Initially, with the IEEE 802.162004, it was designed for small business and residential fixed access users. After that Mobile WiMAX, known as IEEE 802.16e fulfilled the requirement for wireless mobility and supported subscriber stations moving at vehicular speeds. Media Access control (MAC) layer of IEEE 802.16e offers five classes of services to provide different quality of service (QoS) for various demands of the users. Three of them, Unsolicited Grant Service (UGS), extended real-time Polling Service (ertPS) and real-time Polling Service (rtPS) are classified for real- time services, while the non-real-time Polling Service (nrtPS) and best effort (BE) are for non-real-time services. Each service class has its own specific QoS parameters expressed in bandwidth requirement and delay. UGS periodically receives fixed size grants without requesting them. The last included service class, ertPS, has similar grant mechanis $m$ that is used for UGS service class. The difference is that periodically allocated grants can be used for sending bandwidth requests to inform the required grant size. The rtPS service class is providing to subscribers periodic unicast bandwidth request opportunities. These request opportunities guarantee minimum traffic rate and latency bound. The nrtPS service class offers periodic unicast bandwidth request opportunities with more spaced intervals than rtPS and minimum traffic rate guarantee. The last service class, BE, shares with the nrtPS contention bandwidth request opportunities .

Packet scheduling algorithm and call admission control algorithm are the core of the resource management and resource allocation of the WiMAX technology. Packet scheduling in the uplink direction at the base station (BS) is more challenging than scheduling at the downlink direction. It is more complex because it takes into account all QoS parameters defined by the standard and it doesn't have direct access to the connections queues. The uplink scheduler is dependent on the bandwidth requests that are sent by the subscriber stations in order to keep information on each connection status. The bandwidth requests can suffer from delays that can be generated by the contention mechanism. The requests may be also lost because of the channel noise causing outdated info.

There are many solutions that are proposed for uplink scheduling algorithms. The uplink schedulers proposed in [1-3] are based on simple implementable ideas. The uplink scheduler that is proposed in [1] does not provide maximum latency guarantees, and the one explained in [2] proposes a priority value computed by the subscriber stations (SSs) in order to provide latency and rate guarantees. The proposed uplink scheduler in [3] is 
standard-compliant scheduling solution for the uplink traffic in IEEE 802.16 and it uses three queues, low, intermediate and high priority queue. It supports maximum sustained traffic rate, minimum traffic rate, maximum latency and maximum traffic burst requirements. In [4] a fair uplink scheduler is presented that is based on the values of TCP timeout and congestion window and on the channel conditions. Authors in [5] propose a cross-layer scheduler that operates with a mechanis $m$ that dynamically adjusts the size of the uplink and downlink subframes according to the network conditions. The scheduling mechanism proposed in [6], in order to guarantee latency requirements for real time applications, classifies packets in 4 classes. This classification is based on the history of the delays of the packets and higher priority is given to the subscriber stations that have better channel conditions. But, authors in this paper do not provide minimum rate guarantees. Authors in [7] propose an uplink scheduling algorithm that assigns priority values to the connections on the basis of the service class priority, the delay of the packets, the status of the queue and the quality of the channel. But, in the performance evaluation of this scheduler BE service class is not included.

The work presented in this paper extends the uplink scheduler solution proposed in [3], so that we introduce five levels of priority from 1 to 5 ( 1 is the highest and 5 is the lowest priority value) that are applied respectively to the five service classes, ertPS, UGS, rtPS, nrtPS, and BE. In this way bandwidth allocation decisions, besides the level of priority of the three queues proposed in [3], also take into account the level of priority of each service class according to our proposed scheme.

Simulation results present that our proposed uplink scheduling scheme improves the QoS performances measured in average delay, average jitter and average throughput, after implementing it in ns - 2 and comparing it with the results that can be obtained using the uplink scheduling mechanism proposed in [3]. Our solution especially obtains better QoS performances for the newest service class - ertPS without degrading other four service classes and in some cases even getting better results for them, too.
The rest of this paper is organized as follows. Section 2 describes the uplink scheduling principles in mobile WiMAX. Section 3 presents the proposed uplink scheduling scheme. Section 4 describes the simulation environment used to evaluate the proposed uplink scheduling scheme. After that, simulation results are presented in Section 4 and Section 5 concludes the paper.

\section{Uplink Scheduling in Mobile WiMAX}

In the point-to-multipoint mode in Mobile WiMAX technology the base station (BS) communicates with several subscriber stations (SS) in the WiMAX cell. Connections that are made between the BS and the SS are identified by a CID (Connection Identifier) and are structured in frames. One CID can present one application or a group of applications. When the transmission of the traffic is from the SSs to the BS, it is called uplink transmission (UL). When the transmission is in the opposite direction from the BS to the SSs, it is called downlink (DL) transmission. The admission of the new connection is performed by the BS on the basis of the current situation with the available resources. If the QoS requirement of the requested bandwidth is supported the BS will generate CID and Service Flow Identifier and will notify the SS. The admission control algorithm will accept a new connection when this condition will be fulfilled:

$$
C_{\text {reserved }}+T R_{i}^{\text {service }} \leq C
$$

$T R_{i}^{\text {service }}$ is the traffic rate of the new connection $i$ of one of the WiMAX service types denoted with service. In (1) the already reserved capacity is denoted with $C_{\text {reserved }}$ and it is equal to:

$$
C_{\text {reserved }}=\sum_{i=1}^{n} T R_{i}^{\text {service }}
$$

The whole capacity that is available for the uplink scheduler is denoted with $C$. It is the a mount of uplink bandwidth that can be allocated by the uplink scheduler for transmission and unicast polling.

Table 1: Mobile WiMAX service classes and QoS

\begin{tabular}{|c|c|c|}
\hline WiMAX service class & Applications & QoS Specification \\
\hline $\begin{array}{c}\text { UGS } \\
\text { Unsolicited Grant Service }\end{array}$ & VoIP & $\begin{array}{c}\text { Maximum Sustained Rate; } \\
\text { Maximum Latency; Tolerance; Jitter Tolerance }\end{array}$ \\
\hline $\begin{array}{c}\text { rtPS } \\
\text { Real-Time Polling Service }\end{array}$ & $\begin{array}{c}\text { Streaming } \\
\text { Audio or Video }\end{array}$ & $\begin{array}{c}\text { Minimum Reserved Rate; Maximum Sustained Rate; } \\
\text { Maximum Latency; Tolerance; Traffic Priority }\end{array}$ \\
\hline $\begin{array}{c}\text { ertPS } \\
\text { Extended Real-Time Polling Service }\end{array}$ & $\begin{array}{c}\text { Voice with Activity Detection } \\
\text { (VoIP) }\end{array}$ & $\begin{array}{c}\text { Minimum Reserved Rate; Maximum Sustained Rate; } \\
\text { Maximum Latency; Tolerance; Traffic Priority }\end{array}$ \\
\hline nrtPS & File Transfer Protocol (FTP) & $\begin{array}{c}\text { Minimum Reserved Rate; Maximum Sustained Rate; } \\
\text { Traffic Priority }\end{array}$ \\
\hline Non-Real-Time Polling Service & $\begin{array}{c}\text { Data Transfer, } \\
\text { Web Browsing }\end{array}$ & $\begin{array}{c}\text { Maximum Sustained Rate; } \\
\text { Traffic Priority }\end{array}$ \\
\hline Best-Effort Service & & \\
\hline
\end{tabular}


The scheduling schemes in the MAC layer in Mobile WiMAX are designed to deliver successfully different service classes to the users over the wireless channel. The set of QoS parameters of the five scheduling types at MAC layer (UGS, rtPS, ertPS, nrtPS, BE) are presented in Table 1.

There are three different scheduling categories in the Mobile WiMAX networks. Two of them are located at the WiMAX base stations and one at the subscriber stations. DL-BS and UL-BS are the first two scheduling processes that are located at the BS and the third is used for uplink located at the SSs after receiving grants from the UL-BS scheduler. The UL-BS scheduling process is the most complicated because when the WiMAX base station makes scheduling decisions it has no updated information about the current queue status at the SSs. Due to this, the WiMAX BS estimates the current queue status on the basis of the bandwidth requests received from the SSs. The DL-BS scheduling process is much easier because the base station has the current information about the queue status of all downlink connections.

During the uplink transmission of the data, packets are queued at the SSs. In this position the uplink scheduler operates on a request-grant basis. Each SS sends a message with a bandwidth request to the base station. After receiving the bandwidth request messages, they are classified according to the QoS parameters and service classes in the scheduler and bandwidth allocation process starts. In the UL-MAP an Information Element (IE) is responsible for the new resource assignments and control region that SSs should transmit. The UL-MAP is located in each frame at the beginning of its DL subframe. Each SS identifies CID of the broadcast MAP message and then decodes the IE of the UL-MAP. After this, the packets are sent according to the allocated slots.

The newest class of the WiMAX standard - ertPS combines the efficiency of the UGS and rtPS classes. The allocation of slots is similar to the rtPS class.

$$
\begin{aligned}
& N_{i}^{\min }=N_{i}^{\max }= \begin{cases}1, & R_{i}=0, \\
{\left[\frac{T_{i}}{S_{i} F P S}\right],} & R_{i}>0,\end{cases} \\
& \forall i \mid C_{i}=e r t P S
\end{aligned}
$$

$N_{i}$ stands for the number of slots within each frame, $R_{i}$ is the request size, $T_{i}$ stands for bandwidth requirement of the $i$ th connection, $S_{i}$ stands for the slot size, FPS stands for the number of frames the WiMAX BS sends per one second, i.e. the number of bytes a connection can send in one slot, and $C_{i}$ stands for the $i$ th connection class.

It is interesting to note that the ertPS connection can also send the bandwidth requests during the contention period. Bandwidth requests can be updated with a minimum delay. The requested bandwidth should be:

$$
T_{\text {ertPS,req }}=\max \left(T_{B W_{-} R E Q}, n_{i}\left[T_{M A C} / T_{v o i c e}\right] T_{p}\right.
$$

Seconds per MAC frame, where $n_{i}$ is the total number of active connections at the time of making the bandwidth request, $T_{B W-R E Q}$ is the time for transmitting one bandwidth request message, $T_{M A C}$ is the duration of one MAC frame, $T_{\text {voice }}$ is the voice packetization time and $T_{p}$ is the transmission time required for each voice packet. The amount of granted bandwidth is equal to $\min \left(T_{\text {ertPS,req }}, T_{\text {ertPS,max }}\right)$ seconds per MAC frame, where $T_{\text {ertPS,max }}$ is the maximum amount of time available for the SS in an uplink subframe.

For the ertPS service, the maximum amount of time that each SS is allowed to transmit is given by:

$$
T_{\text {ertPS,max }}=\frac{T_{M A C_{-} U P}-T_{\text {overhead }}}{N_{S}}
$$

$N_{s}$ is the number of connections associated to subscriber stations (SSs) $i, i=1,2, \ldots N_{s}, T_{M A C_{-} U P}$ is the duration of one MAC frame in uplink, $T_{\text {overhead }}$ is initial ranging period duration.

Packet transmission performance using the ertPS service strongly depends on the MAC frame size. With a short MAC frame duration, using the ertPS service we achieve approximately as good packet transmission performance as using the UGS service. As the frame size increases, the packet transmission performance using the ertPS service degrades.

\section{Proposed Uplink Scheduling Scheme}

During the implementation of our proposed priority scheduling scheme we assumed that each SS carries single service flow. In this way the interpretation of the uplink scheduler at the BS is eased. Our proposed solution for the uplink scheduling at the SSs is based on a strict priority scheduling as it is shown in Table 2 .

Table 2: Priority of WiMAX service classes

\begin{tabular}{|c|c|}
\hline WiMAX Service Class & Priority Assigned \\
\hline ertPS & 1 \\
\hline UGS & 2 \\
\hline rtPS & 3 \\
\hline nrtPS & 4 \\
\hline BE & 5 \\
\hline
\end{tabular}

According the proposal ertPS service class has the highest priority and is served first. The proposed solution for uplink scheduling at the SSs is implemented on the basis of the scheduling mechanism explained in [3]. The architecture of the proposed uplink scheduler is presented in Fig. 1. 


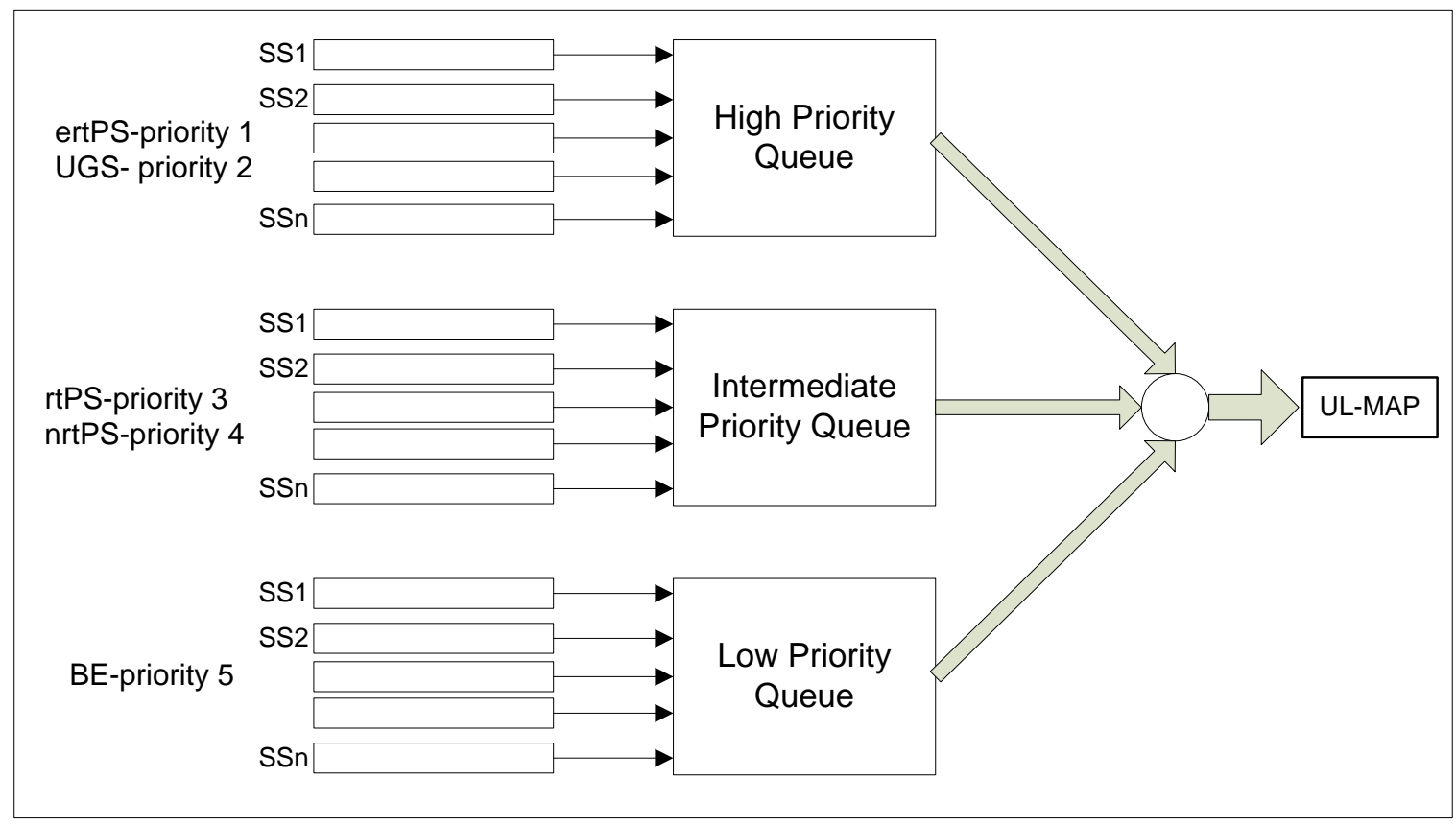

Fig. 1: Architecture of the proposed uplink scheduler

The scheduling mechanis $\mathrm{m}$ in [3] uses three queues, high priority, intermediate priority and low priority queue. The queue with low priority is used for the BE bandwidth requests, the intermediate queue is reserved for storing the bandwidth request sent by rtPS and nrtPS service classes and the high priority queue is reserved for UGS and ertPS service classes. Bandwidth requests sent by both rtPS and nrtPS connections can migrate to the high priority queue to meet their QoS require ments. After upgrading the scheduling mechanism in [3] that uses queues divided into three categories with our proposed priority-based uplink scheduling, we compared our proposed solution with the solution in [3].

Our proposed uplink scheduler is based on the class priority level with respect to other classes. Each service class is assigned with the priority as it is shown in Table 2. We use values from 1 to 5 for the class priority level according the ns -2 classification where priority 1 is the highest priority. The priority levels were set as follows: 1 for the ertPS service class, 2 for the UGS service, 3 for the rtPS service, 4 for the nrtPS service and 5 for the BE service. Although ertPS and UGS services are in the same high priority queue, with our added priority when ertPS and UGS are active services in the same time, ertPS traffic will have higher priority for uplink scheduling than UGS. Priority values of 3 and 4 are set for rtPS and nrtPS service connections, respectively, that are in the intermediate queue. This means that rtPS service class has higher priority in uplink scheduling than nrtPS service class, although they are in the same intermediate priority queue. We set higher priority for rtPS service class because it is delay sensitive service. Finally, BE service class that is in the low priority queue has priority value of 5. It is last in the uplink scheduling scheme. Our proposed solution is compared with the performances of the scheduling mechanism presented in [3] in terms of average delay, average jitter and average throughput in different scenarios with different loads of the network. As we can see from the next section our results are better.

The proposed uplink scheduling scheme is presented in the next explanation of the steps that the algorith $m$ is executing:

Insert in the queue with high priority unicast request opportunities and the periodic data grants that must be scheduled in the next frame;

$>$ Check if rtPS and nrtPS requests can migrate from the queue with intermediate priority to the queue with high priority with the procedures "check the deadline" and "check the minimum bandwidth". In both cases the class priority level of rtPS and nrtPS service classes ( 3 and 4 ) remains the same, i.e. they are served after ertPS and UGS service classes with class priority levels of 1 and 2;

Uplink scheduler distributes among the BE connections the non-allocated bandwidth. BE service class has the last class priority level, that is 5;

Finally, the uplink scheduler serves all the requests at the queue with high priority firstly and the service class with the highest priority level that is ertPS.

\section{Simulation Environment and Results}

\subsection{Simulation Environment}

In the research community one of the most popular tools is the Network Simu lator (ns-2). For simulation of IEEE 802.16-based networks using ns-2 several modules were proposed. One of them is implemented 
by NIST - National Institute of Standards and Technology, but it fails to implements MAC QoS support. Another simulation module for IEEE 802.16 that is presented in [8] provides packet frag mentation and packing, but users cannot configure QoS requirements. There is also a group that developed an 802.16-based simulator for the OPNET tool, but it is a private domain simulator. We have evaluated that the most adequate simulator for WiMAX service classes is the module designed by the group of the University of Campinas [9]. This module is focused on the MAC layer and its mechanis ms for bandwidth allocation and QoS support.

The topology of the simulated network for the simulation scenarios done in this paper consists of a BS located at the center of a $250 \times 250$ meter area, with the SSs uniformly distributed around it. We enabled random motion to the SSs by setting the random-motion to 1 in $\mathrm{ns}-2$, in which case random destinations are assigned to the nodes. Each SS has one uplink flow and one downlink flow, which are mapped to the same service type. Five types of traffic are used: voice, voice with silence suppression, video, FTP, and WEB, which are associated with UGS, ertPS, rtPS, nrtPS, and BE services, respectively. Each of the SSs has only one service flow in order to eliminate the impact of the packet scheduling at the SSs on uplink scheduling.

We used as a voice model for UGS service class an exponential model with mean duration of 1.2 seconds of the "on period" and 1.8 seconds of the "off period", respectively. For UGS service class according this model packets of 66 bytes are generated every 20 milliseconds. For simulating ertPS service class we used in the simulator EVRC - Enhanced Variable Rate Codec as a model of voice with silence suppression [10]. In our scenarios rtPS service class was simulated using real MPEG traces. nrtPS service class in the simulator that we use is generated with FTP traffic using an exponential distribution with a mean of 512 KBytes. BE service class is simulated with WEB traffic that is modeled in the simulator by a hybrid Lognorma1/Pareto distribution with the body of the distribution modeled by a Lognormal distribution with a mean of 7247 bytes and the tail modeled by a Pareto Distribution with mean of 10558 bytes.

UGS and ertPS service class es have unsolicited grant interval of 20 milliseconds. rtPS has unsolicited polling interval of $20 \mathrm{~ms}$ and nrtPS of 1 second. BE service class doesn't have any QoS requirement. The number of UGS, rtPS, nrtPS and BE connections is equal to 10 in all of the simulated scenarios. We only change the number of ertPS connections from 5 to 30 in order to test the performances under different ertPS traffic load. The duration of each simu lation scenario is 100 seconds. Each simulation scenario was running ten times with different seeds. In the figures we show the mean values and the $95 \%$ confidence intervals.
The free space model and the two-ray model in ns-2 predict the received power as a deterministic function of distance. They both denote the communication range as an ideal circle. But, in the reality, the received power at some distance is a random variable due to multipath propagation effects, known as fading effects. The free space model and the two-ray model predict the mean received power at distance $d$. Widely-used model that is more general is called the shadowing model. All of the simulated scenarios in our work are using the Shadowing propagation model. This model consists of two parts. The first part is the path loss model. It predicts the mean received power at some distance $d$, denoted by $\overline{P_{r}(d)}$. Close-in distance $d_{0}$ is used as a reference. $\overline{P_{r}(d)}$ is computed relative to $P_{r}\left(d_{0}\right)$ as follows:

$$
\frac{P_{r}\left(d_{0}\right)}{\overline{P_{r}(d)}}=\left(\frac{d}{d_{0}}\right)^{\beta}
$$

$\beta$ is denoted as path loss exponent which is usually determined empirically by measurements on the field. The value of the path loss exponent is 2 in all of the simulated scenarios. It is typical value for free space propagation. Because the path loss exponent is measured in $\mathrm{dB}$ in most cases, from (6) we have:

$$
\left[\overline{\frac{P_{r}(d)}{P_{r}\left(d_{0}\right)}}\right]_{d B}=-10 \beta \log \left(\frac{d}{d_{0}}\right)
$$

The second part of this model used in our simulations reflects the variation of the received power and it can be presented by the following equation:

$$
\left[\overline{\frac{P_{r}(d)}{P_{r}\left(d_{0}\right)}}\right]_{d B}=-10 \beta \log \left(\frac{d}{d_{0}}\right)+X_{d B}
$$

$X_{d B}$ is a Gaussian random variable with zero mean at standard deviation denoted with $\delta_{d B}$. This standard deviation $\delta_{d B}$ is sometimes called the shadowing deviation. This value is also obtained empirically by measurements. In our simulations this value was set to 4 .

In order to investigate the impact of the proposed uplink scheduling algorithm on different load of ertPS traffic while the other four services has the same load in the scenarios, we varied the number of ertPS connections from 5 to 30 with a step of 5 connections. So, we made 6 scenarios where each of the other 4 service classes had 10 connections, while the number of ertPS connections was 5,10,15,20, 25 and 30. The results are shown in average jitter, average delay and average throughput for all five service classes. 


\subsection{Simulation Environment}

Fig. 2 presents the average delay of variable number of ertPS connections from 5 to 30 and average delay of 10 UGS connections in all six cases of different load of ertPS connections. UGS-default and ertPS-default in Fig. 2 denote the results obtained with the scheduling mechanis $m$ in [3], and UGS-new and ertPS-new denote the results obtained with our modified scheduling scheme. It is obvious from Fig. 2 that after apply ing our priority based scheme results for ertPS connections are better. In the same time average delay of UGS connections is not degraded after the implementation of the proposed scheduling scheme. Values of average delay of 10 UGS connections are not affected after implementing our proposed scheduling scheme. We can also conclude from Fig. 2 that the increase of the ertPS traffic load has no influence on the average delay of UGS connections in both cases. This happens because UGS service class is in the queues with high priority together with ertPS service class.

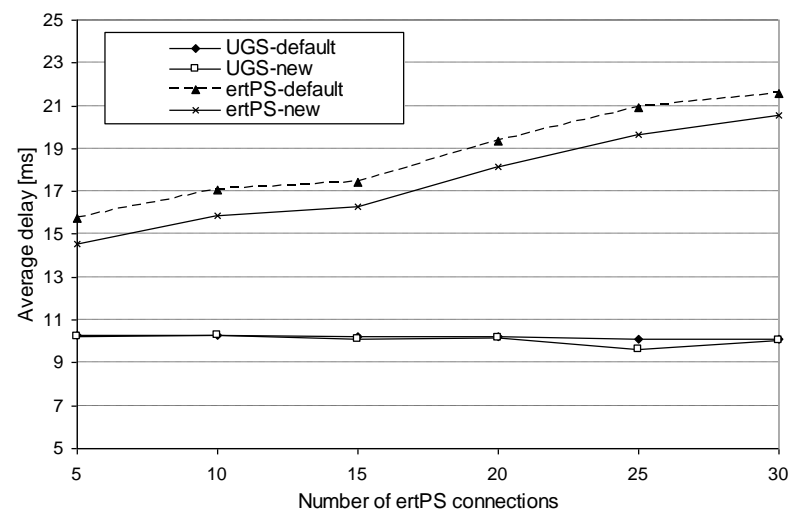

Fig. 2: Average delay of 10 UGS connections under different load of ertPS connections

Fig. 3 presents average delay of $10 \mathrm{rtPS}$ connections after 10 iterations in ns-2 while the ertPS connections varies from 5 to 30 connections. Since rtPS service class is in the queue with intermediate priority, the increase of the ertPS traffic load influences the average delay of the rtPS service class. Modification of the scheduling mechanis $\mathrm{m}$ in [3] with our added strict priority for all five service classes where we give the highest priority to ertPS service class doesn't have a negative effect on the average delay results for rtPS service class. Contrary, in the simulations that we have done, we have even better results in some of the scenarios (when number of ertPS connections are 5, 15, 20, 25). We verified with the results in Fig. 3 that the average delay of $10 \mathrm{rtPS}$ connections in all six cases with variable load of ertPS connections (from 5 to 30), didn't violate the maximum latency requirement of 100 ms.

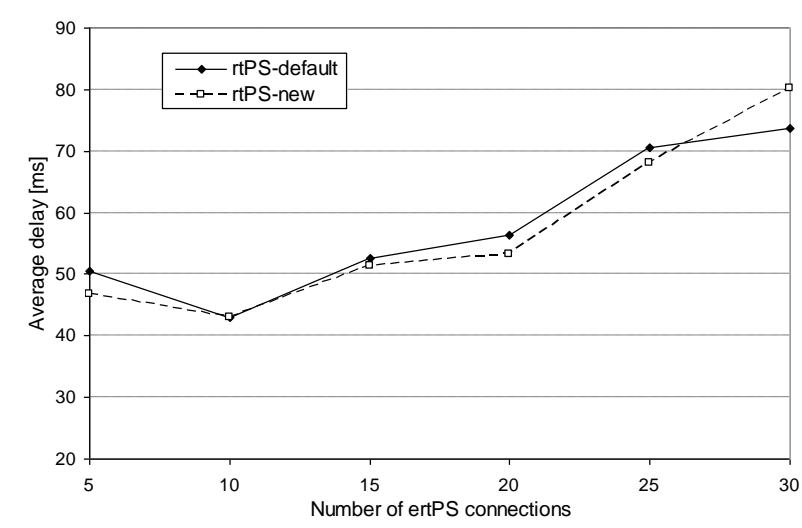

Fig. 3: Average delay of $10 \mathrm{rtPS}$ connections under different load of ertPS connections

Fig. 4 shows the average delay results for $10 \mathrm{nrtPS}$ and $10 \mathrm{BE}$ service classes under the same six cases of different load with ertPS traffic. The average delay values of 10 nrtPS connections fluctuate around 3 seconds in both cases. BE service class is in the low priority queue and has the lowest priority according our scheduling scheme. Consequently, it has the worst average delay results in Fig. 4. Furthermore, we can verify here that the increase of the ertPS traffic load has impact on the average delay results for the BE service class. Our proposed uplink scheduling priority scheme hasn't changed significantly the average de lay results of nrtPS and BE service classes under different traffic load of ertPS connections.

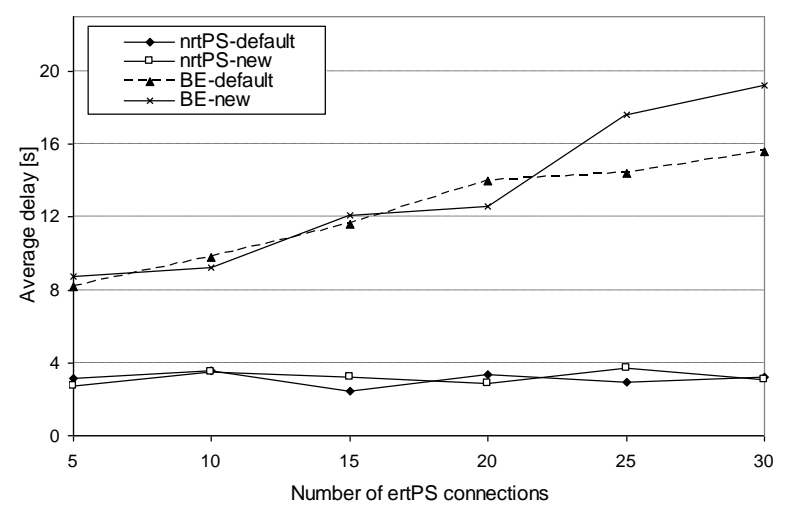

Fig. 4: Average delay of $10 \mathrm{nrtPS}$ and $10 \mathrm{BE}$ connections under different load of ertPS connections

Although the average delay results are not very important for nrtPS and BE service classes for measuring the QoS of the uplink scheduling mechanism, we have presented them here to compare the possibilities of our proposed scheduling scheme to the one in [3].

Fig. 5 presents the average jitter results for UGS and ertPS connections. Similarly to average delay results, average jitter results for ertPS service class are better using the proposed scheduling scheme compared to the scheduling mechanism in [3]. Average jitter results for UGS service class are in both cases not affected by the 
increase of the ertPS connections. Their values are under or around $6 \mathrm{~ms}$ in all of the simulated scenarios in both cases.

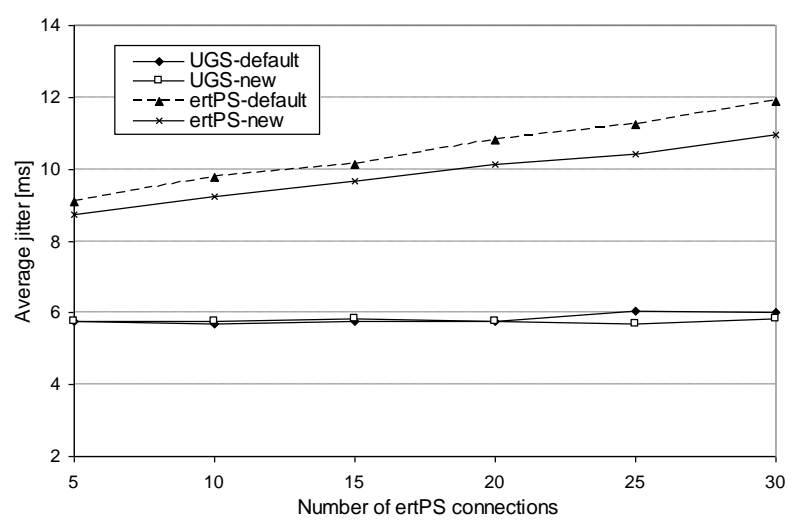

Fig. 5: Average jitter of 10 UGS connections and average jitter of ertPS connections varying from 5 to 30 subscriber stations

Fig. 6 shows the average jitter results for $10 \mathrm{rtPS}$ connections under different ertPS traffic load comparing the uplink scheduling mechanism (denoted with rtPS-default) in [3] with our proposed scheduling scheme (denoted with rtPS-new). Compared results show that our proposed scheduling scheme gives even a little better results for this service class.

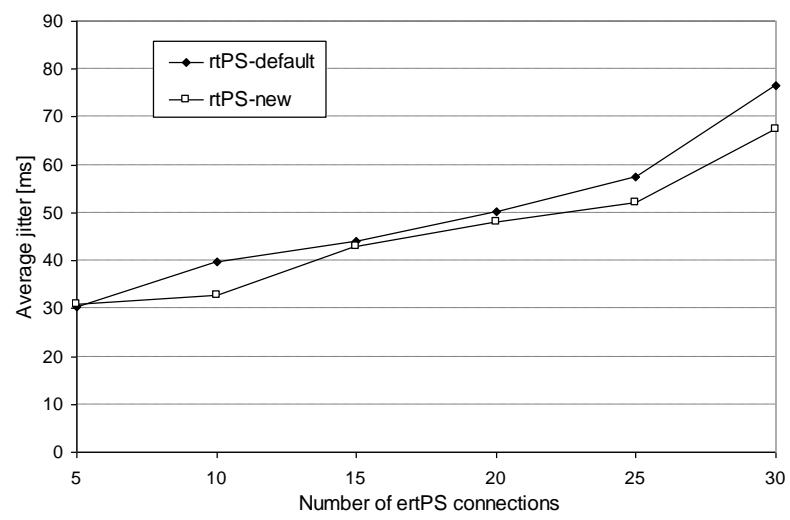

Fig. 6: Average jitter of 10rtPSconnections under different load of ertPS connections

Average throughput results are shown from Fig. 7 to Fig. 9 for all five service classes. Although average throughput results are not of great importance when measuring QoS for ertPS and UGS, we present them too in order to verify and compare our proposed uplink scheduling scheme. The number of UGS, rtPS, nrtPS and $\mathrm{BE}$ connections is 10 in all cases. Results show that our solution gives better average throughput results for ertPS service class for all levels of load from low -5 to high-30.

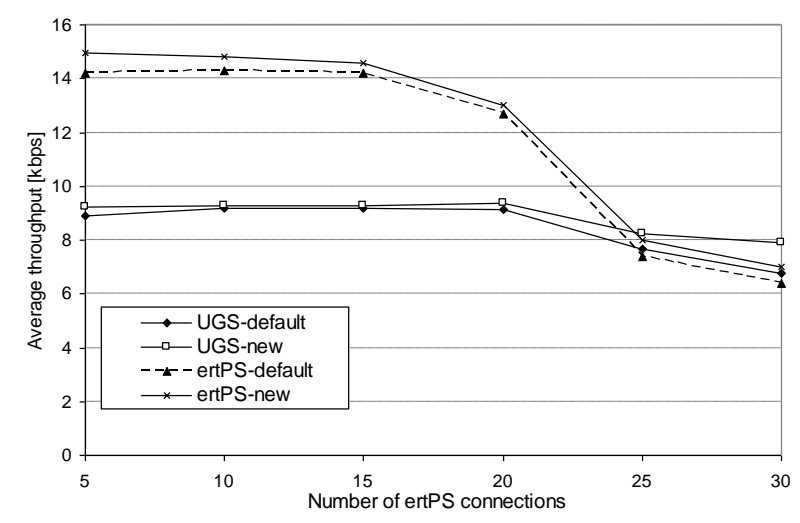

Fig. 7: Average throughput of 10 UGS and 5-30 ertPS connections

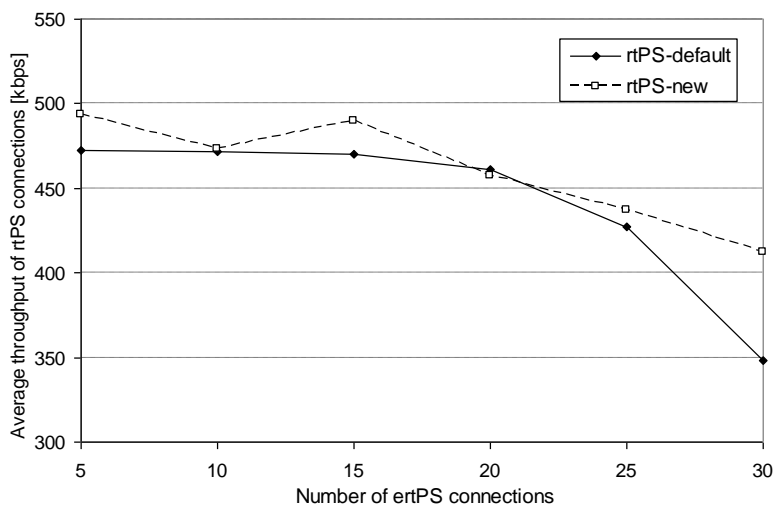

Fig. 8: Average throughput of $10 \mathrm{rtPS}$ connections under different load of ertPS connections

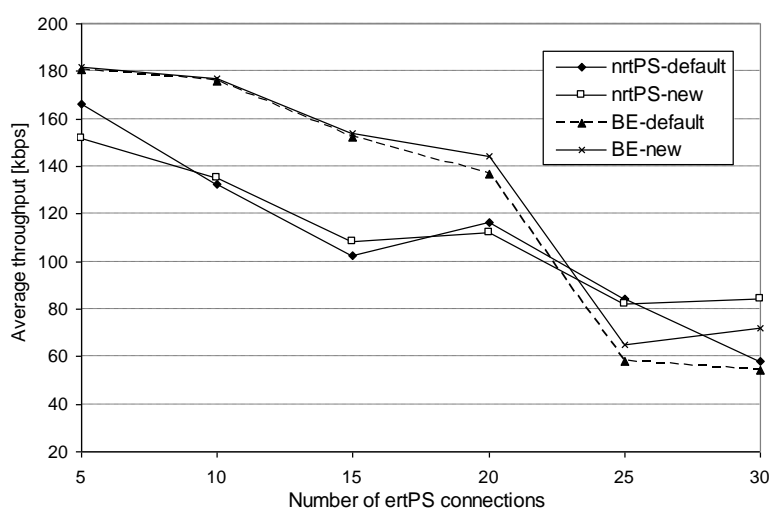

Fig. 9: Average throughput of $10 \mathrm{nrtPS}$ and $10 \mathrm{BE}$ connections under different load of ertPS connections

As the traffic load with ertPS connections gets high (25 and 30 ertPS connections), average throughput of all five service classes drops in both cases. But, in the high load scenario cases, average throughput results are better with the proposed uplink scheduling scheme. Average throughput of all five service classes is less affected when the traffic load of the connections gets very high ( 25 or 30 ertPS connections) when we are using our proposed uplink scheduling scheme co mpared to [3]. 
Furthermore, besides comparing the average results of $10 \mathrm{rtPS}$ connections of our proposed uplink scheduling scheme with other schemes, we verify in Fig. 8 the minimum and the maximum traffic rate requirements as specified by the standard. In all of the simulated scenarios, the minimum rate requirement of $300 \mathrm{kbps}$ for the average throughput results of rtPS connections and the maximum rate requirement of 500 kbps were in the range regardless of the network load with ertPS connections.

\section{Conclusion}

In this paper we have proposed and presented a priority based uplink scheduling scheme. It is implemented using the wimax simulator that was developed in [9] in the ns-2 simulation environment. After implementing our uplink scheduling scheme in ns-2, it was tested using a constant load of 10 connections for UGS, rtPS, nrtPS and BE service classes and different ertPS traffic load and compared to the already presented effective uplink scheduling mechanis $m$ in [3]. Presented results in Section 4 show that the proposed priority based scheduling scheme where ertPS service class has the highest priority gives better results in average delay, jitter and throughput compared with the uplink scheduling mechanis $m$ in [3] that uses three queues, low (BE service class), intermediate (rtPS and nrtPS) and high priority queue (UGS, ertPS).

Results are obtained in low and heavy loaded scenarios with ertPS service class from 5 to 30 connections. Each of the 4 service classes have 10 connections, except ertPS connections which number varies from 5 to 30 connections. From the results two types of conclusions has been made. One type of conclusions is made from the influence of the number of ertPS connections on the other service classes in both cases. The other type of conclusions is made from the comparison of our solution and the solution presented in [3]. With the proposed uplink scheduling scheme in this paper the influence of the ertPS traffic load on the other service classes is decreased. Using this scheduling scheme we obtained better results in average delay and jitter for ertPS service class. This gain hasn't decreased the performances in average delay, jitter and throughput of the other service classes. Contrary, in many cases we have even better results in the measured QoS performances of UGS, rtPS, nrtPS and BE service classes.

\section{References}

[1] Sayenko, A., Alanen, O., Hamalainen T. Scheduling solution for the IEEE 802.16 base station.Computer Networks, 52(1), 96-115, 2008.
[2] Bai, X., Shami, A., Ye, Y. Robust QoS control for single carrier PMP mode IEEE 802.16 systems. IEEE Transactions on Mobile Computing, 7(4), 416-429, 2008.

[3] Borin, J. F., da Fonseca, N. Uplink Scheduler and Admission Control for the IEEE 802.16 standard. In Global Telecommunications Conference, GLOBECOM, IEEE. Honolulu, HI, 2009.

[4] Rath, H. K., Karandikar A., Sharma V. Adaptive modulation-based TCP-aware uplink scheduling in IEEE 802.16 networks. In Proceedings of the IEEE International Conference on Communications, IEEE, 2008.

[5] Lai, Y., Chen, Y. A channel quality and QoS aware bandwidth allocation algorithm for IEEE 802.16 base stations. In $22^{\text {nd }}$ International Conference on Advanced Information Networking and Applications, pp. 472-479, IEEE, 2008.

[6] Ho, Q., Ashour, M., Le-ngoc, T. Delay-sensitive and channel-aware scheduling in next generation wireless networks. 2008 Canadian Conference on Electrical and Computer Engineering, pp. 18011804, may 2008.

[7] Lu, J., Ma, M. A cross-layer elastic CAC and holistic opportunistic scheduling for QoS support in WiMAX. Computer Networks, 2009.

[8] J. Chen et al. Design and implementation of WiMAX module for ns-2 simulator: the IP network, Paper No. 5, 2006.

[9] Borin, J. F., da Fonseca, N. Simulator for W iMAX networks. In Simulation Modelling Practice and Theory 16, 817-833, 2008.

[10] 3GPP2 C.S0014-0, Enhanced Variable Rate Codec (EVRC).

\section{Authors' Profiles}

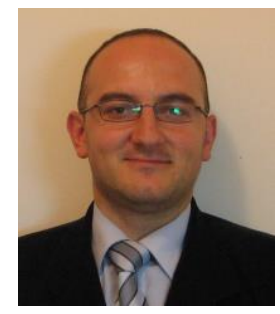

Kire Jakimoski: Received his M.Sc. degree in Electrical Engineering in the field of Telecommunications from the Ss. Cyril and Methodius University in Skopje, R. Macedonia in 2007. He is Ph.D. candidate in the field of Teleco mmunications at the Faculty of Electrical Engineering and Information Technologies, Ss. Cyril and Methodius University in Skopje. From 2002 to 2006 he works in the field of Telecommunications in the Ministry of Defense in the Republic of Macedonia. From January, 2006 to March, 2012 he works as an adviser for information security in the Directorate for Security of Classified Information in the Republic of Macedonia. From March, 2012 he is a Research and Teaching Assistant at the Faculty of Information and Communication Technology, FON University in Skopje, Republic of Macedonia. Also, he 
is an author/co-author of about 20 published research papers. His research interests include Wireless and Mobile Networks, Heterogeneous Wireless Networks, Computer Networks, Quality of Service, Information Security.

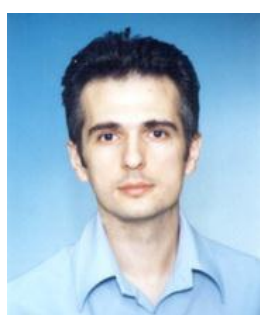

Dr. Toni Jane vski: Profess or at the Faculty of Electrical Engineering and Information Technologies, Ss. Cyril and Methodius University in Skopje, Macedonia. He received his Dipl. Ing., M.Sc. and Ph.D. degrees in electrical engineering all from Faculty of Electrical Engineering and Information Technologies, Ss. Cyril and Methodius University in Skopje, in 1996, 1999 and 2001, respectively. In the past, during 1996-1999 he has worked at the Macedonian mobile operator Mobimak (currently T-Mobile, Macedonia), contributing to the planning, dimensioning and implementation of the first mobile network in Macedonia. From 1999 he is with Faculty of Electrical Engineering and Information Technologies in Skopje. In 2001 he has conducted research in optical communication at IBM T. J. Watson Research Center, New York. Also, during 2005-2008 he was a Member of the Commission of the Agency for Electronic Communications (AEC) of the Republic of Macedonia, where he contributed towards the introduction of new technologies in Macedonia, such as WiMAX and 3G mobile networks, as well as new operators and services. During the periods 2008-2012 and 2012-2016 he is an elected member of the Senate of the Ss. Cyril and Methodius University in Skopje. In 2009 he has established Macedonian ITU (International Telecommunication Union) Centre of Excellence (CoE) as part of the Europe's CoE network, and serves as its Coordinator since than. He is an author of the book titled "Traffic Analysis and Design of Wireless IP Networks", which is published in 2003 by Artech House Inc, Boston, USA. Also, he is author of the book "Switching and Routing", written in Macedonian language, published in September 2011 by the Ss. Cyril and Methodius University in Skopje, for which in May 2012 he has won the "Goce Delchev" award, the highest award for science in the Republic of Macedonia. He has published more than 130 research papers and has led research and applicative projects in the area of Internet technologies and mobile and wireless networks. $\mathrm{He}$ is a Senior Member of IEEE. His research interests include Internet Technologies, Mobile, Wireless and Multimedia Networks, Traffic Theory, Quality of Service, Design and Modeling of Telecommunication Networks, as well as Next Generation Networks.

How to cite this paper: Kire Jakimoski, Toni Janevski,"Priority Based Uplink Scheduling Scheme for WiMAX Service Classes", International Journal of Information
Technology and Computer Science(IJITCS), vol.5, no.8, pp.6674, 2013. DOI: $10.5815 /$ ijitcs.2013.08.07 